\title{
Impact of YouTube advertising on purchase intention: A Pitch
}

\author{
Mehak Rehman a and Haroon Iqbal Maseeh ${ }^{\mathrm{b}, 1}$ \\ ${ }^{a}$ University of the Punjab, Gujranwala Campus, Pakistan \\ ${ }^{\mathrm{b}}$ Griffith Business School, Griffith University, Gold Coast, Australia
}

\begin{abstract}
Internet technology has proved its worth in every field of life. Due to its vast penetration, organisations started using this technology as a marketing platform. YouTube is one of the online platforms which is subscribed by millions of users and has become a reliable chanel for advertising. However, the understanding regarding the effectiveness of YouTube advertising remains limited. Accordingly, this PRL applies the pitching template developed by Faff $(2015 ; 2019)$ to an academic project titled "Impact of YouTube Advertising on Purchase Intention". In this PRL, researchers develop a framework for a research project to identify the core elements of the research. This letter consists of introduction section, followed by pitchers' brief commentary and personal reflection on pitching exercise.
\end{abstract}

Keywords: YouTube advertising, purchase intention, technological marketing, pitching research

JEL codes: M31, M37

\section{Introduction}

The purpose of this letter is to apply the pitching template developed by Faff (2015; 2019) to a research project titled "Impact of YouTube advertising on purchase intention". This is a "real" pitch as we applied the two-page pitching template on our empirical research project. The "pitching template" is a tool which allows for

\footnotetext{
${ }^{1}$ Corresponding author: Department of Marketing, Griffith Business School, Griffith University, 1-Parklands drive, Southport, QLD, 4215. Email: haroon.maseeh@griffithuni.edu.au
} 
articulation of the critical idea, data and methodology and expected contribution of a research project (Machek \& Kubíček, 2019: 443). Starting and ending are the two critical challenges in every research project (Iqbal \& Ashraf, 2017; Maseeh, 2019). Professor Robert Faff's work provides a guideline to researchers to overcome such challenges for a timely completion of their research projects (Faff, 2015; Faff et al., 2017).

In our study, we will investigate the impact of YouTube advertising on customers' purchase intention. Launched in 2005, YouTube is a well-regarded social media platform which enables its users to post, watch, like or dislike and comment on shared contents (i.e. videos). In every minute, 100 hours of videos are uploaded on YouTube. More than one billion users visit this site per month. These visitors watch approximately six billion hours of videos every month and like, share, and comment on various videos. These calculations make YouTube the $3^{\text {rd }}$ highly visited website in the world (Dehghani et al., 2016).

In the next section of this letter, we have discussed a brief commentary on pitching exercise followed by the completed pitch. In the third section, we have elaborated our personal reflection on pitching exercise. It is followed by the conclusion section.

\section{Brief commentary on the pitching exercise}

Our completed pitch titled "Impact of YouTube advertising on purchase intention" is presented in Table 1 (Item A). The primary research question is what is the impact of YouTube advertising on purchase intention? (Item B). The key research papers (KPs) related to the research question are Dehghani et al. (2016), Yang, Huang, Yang, and Yang (2017), and Sokolova and Kefi (2020) (Item C). Selection of key research papers fulfil the criteria suggested by Faff et al. (2017):

1) Recently published;

2) Top-tier journals; and

3) By the experts in the field.

The first key research paper Dehghani et al. (2016) titled "Evaluating the influence of YouTube advertising for attraction of young customers" examines the factors that influence customers' purchase intention. This paper is published in "Computers in Human Behaviour" which is a well reputed journal and have an impact factor 5.003 in Journal Citation Report (JCR) 2020.

The second key research paper Yang et al. (2017) titled "Consumer attitudes toward online video advertisement: YouTube as a platform " investigates customers' attitude towards YouTube advertising while they watch online videos on YouTube. This 
paper is published in "Kybernetes", a well reputed journal with JCR impact factor 1.754 .

The third key research paper Sokolova and Kefi (2020) titled "Instagram and YouTube bloggers promote it, why should I buy? How credibility and para-social interaction influence purchase intentions" examines the influence of physical attractiveness, attitude homophily, social attractiveness, credibility, and para-social interaction of Instagram and YouTube bloggers on customers purchase intention. This paper is published in "Journal of Retailing and Consumer Services" which has 4.219 impact factor in JCR.

Our research will examine the effectiveness of YouTube advertising considering entertainment, informativeness, customisation, and irritation as independent variables, and advertisement value and brand awareness as mediators that in turn influence customers' purchase intention which is the dependent variable. The findings will help understand customers' intention to purchase a product advertised on YouTube. Accordingly, this research will contribute to the literature on electronic and social media marketing.

\section{Personal reflection on the pitch exercise}

Making a sound start is the most challenging step in a research (Faff, 2019). This is because a researcher needs to affirm that the proposed research idea is novel and will contribute to theory and practice. It is only possible when a researcher reviews the extant literature in the area of study. Although pitching exercise can be daunting for some researchers (Nguyen, 2020), we found pitching exercise quite useful. That is, showing a clear picture of research gap and significance of the research, pitching exercise helped us communicate research ideas in a succinct and concise manner. It enabled us to draft a research plan in "4-3-2-1" template where " 4 " depicts working title, basic research questions, key papers, and motivation; "3" specifies three fundamental components of this research project i.e. idea, data, and tool; " 2 " shows two important questions, i.e. what's new? and so what?; and "1" demonstrates contribution of the research.

Drawing a Mickey Mouse diagram in pitching exercise enables researcher(s) to demonstrate their overall research plan and its outcomes in a simple and easily understandable manner. In pitching exercises, researchers have used Mickey Mouse diagrams to present scope of research (e.g. Iqbal \& Ashraf, 2017; Raut, 2019; Nguyen, 2020). We also developed the Mickey Mouse diagram for our research project (see Figure 1) which demonstrates the novelty of our research idea. 
Table 1. Completed research pitch template on Impact of YouTube advertising on purchase intention

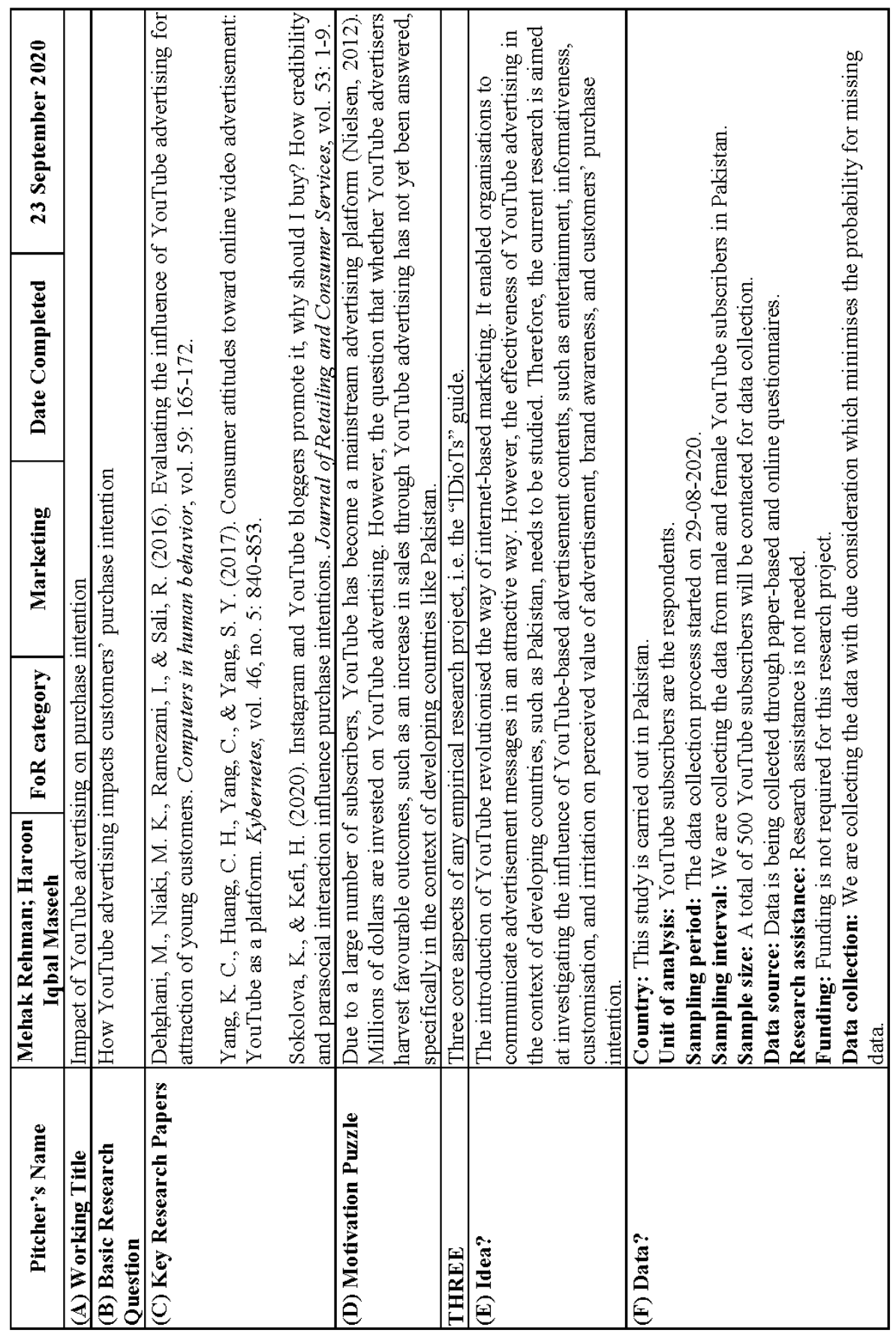




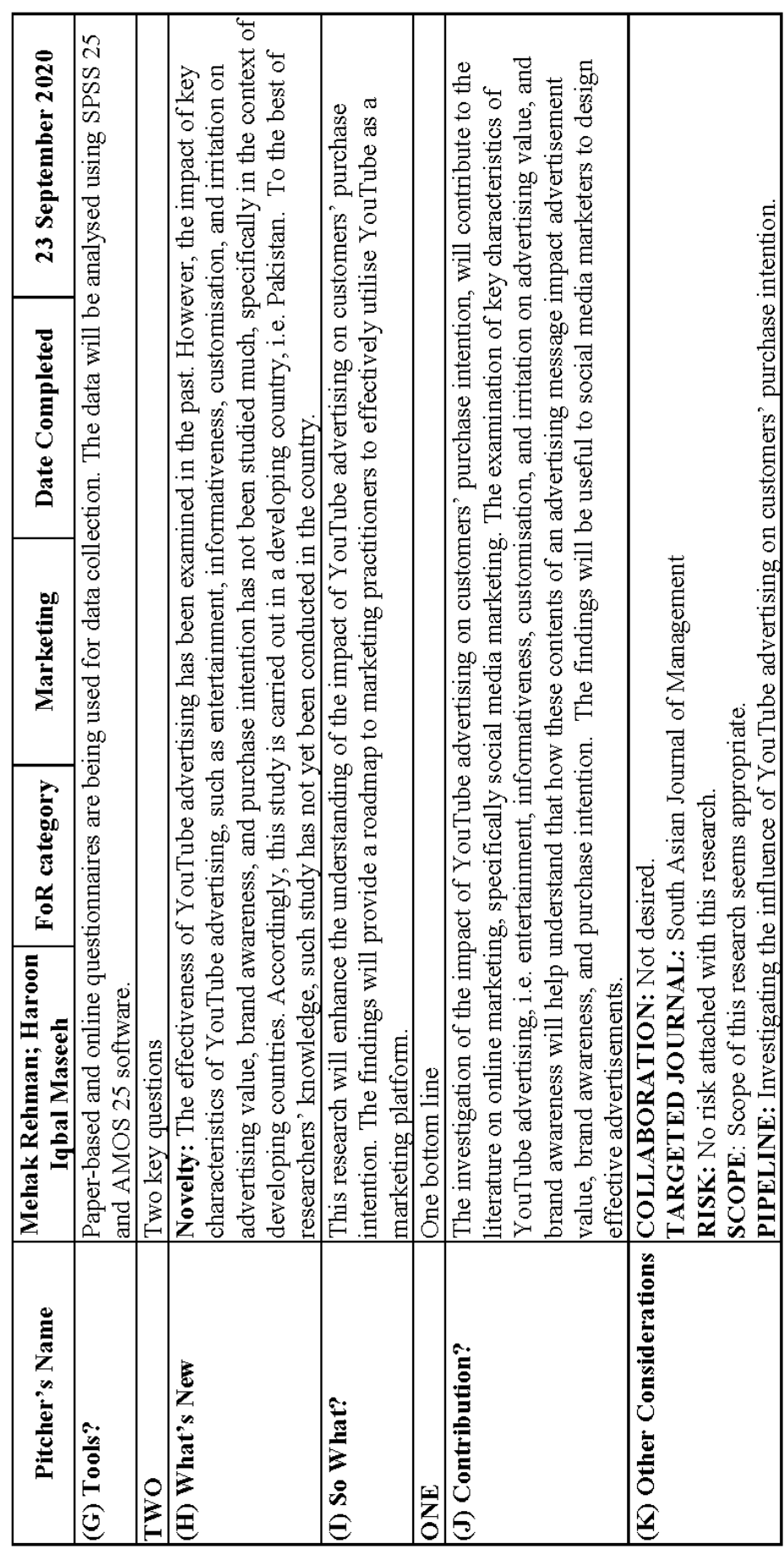

Vol. 19, No. 4 


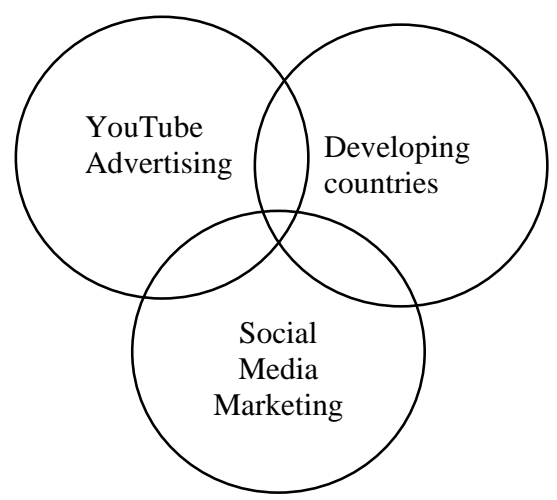

Figure 1: Mickey Mouse diagram characterizing novelty of the research idea

\section{Conclusion}

Academics are extremely busy individuals and have limited time to read every single page of a research proposal. Pitching research approach helps novice researchers present a comprehensive information regarding their research project in a compact, systematic, and efficient way (Macheka \& Kubíčeka, 2019). Based on the PRL template proposed by Faff, (2015; 2019), this PRL applies the pitching exercise on an academic project titled "Impact of YouTube advertising on purchase intention". We find the pitching exercise useful for novice and early career researchers.

\section{References}

Dehghani, M., Niaki, M. K., Ramezani, I., \& Sali, R. (2016) "Evaluating the influence of YouTube advertising for attraction of young customers", Computers in Human Behavior, vol 59: 165-172

Faff, R.W. (2015) “A simple template for pitching research”, Accounting \& Finance, vol. 55, no. 2: 311-336

Faff, R.W. (2019) "Pitching Research", Available at SSRN: http://ssrn.com/abstract=2462059

Faff, R., Ali, S., Atif, M., Brenner, M., Chowdhury, H., Crudas, L., Joubet, A., Malik, I., Mi, L., Nagar, V., Pullen, T., Siegrist, M., Smythe, S., Stephenson, J., Zhang, B. \& Zhang, K. (2017) "Fantasy Pitching", Accounting and Management Information Systems, vol. 16, no. 2: 360-379

Iqbal, H. \& Ashraf, H. A. (2017) "Impact of behavioral factors towards the adoption of mobile learning among higher education students in public and private universities: A pitch", Accounting and Management Information Systems, vol. 16, no. 3: 406-412 
Macheka, O. \& Kubíčeka, A. (2019) "Socioemotional wealth in gay-owned family businesses: A pitch", Accounting Management Information Systems, vol. 18, no. 3: 443-449

Maseeh, H. I. (2019) "Digital mobile advertising: A Pitching research letter", Accounting and Management Information Systems, vol. 18, no. 4: 640-646

Nguyen, Q. (2020) "Corporate governance and earnings management in Vietnamese listed firms: A pitch", Accounting and Management Information Systems, vol. 19, no. 1: 179-188

Raut, S. (2019) "Occurrence of occupational fraud in family businesses: A Pitch", Accounting and Management Information Systems, vol. 18, no. 1: 119-125

Sokolova, K. \& Kefi, H. (2020) "Instagram and YouTube bloggers promote it, why should I buy? How credibility and parasocial interaction influence purchase intentions", Journal of Retailing and Consumer Services, vol. 53: 1-9

Yang, K.-C., Huang, C.-H., Yang, C., \& Yang, S. Y. (2017) "Consumer attitudes toward online video advertisement: YouTube as a platform", Kybernetes, vol. 46 , no. 5: $840-853$ 